
\title{
R Research Square \\ Experimental and Simulated Comparison of Finite Element Models of Bimetallic Sheets for Deep Drawing Process
}

Cengiz Görkem Dengiz ( $\nabla$ gorkem.dengiz@omu.edu.tr )

Ondokuz Mayıs University https://orcid.org/0000-0003-1308-3223

Kemal Yildizli

Ondokuz Mayıs University

\section{Research Article}

Keywords: bimetallic sheets, FEM, deep drawing, cohesive zone model, Columb friction

Posted Date: June 11th, 2021

DOl: https://doi.org/10.21203/rs.3.rs-405701/v1

License: (c) (1) This work is licensed under a Creative Commons Attribution 4.0 International License.

Read Full License 


\section{Abstract}

In this study, different techniques using for modeling of bimetallic sheets by finite elements method has been compared. Sheets modeled with 5 different assumptions were compared with each other and experimental datas, to determine the FE model that gives the most realistic result. FE models were created with the assumption that the adhesion was excellent or separable, and with the case that the solidified adhesive in the intermediate layer was modeled and not modeled. As a result, the closest values to the experimental results were obtained with the model created with the assumption that there is a solidified adhesive layer in the middle layer and there is an adhesion interface between this layer and metallic layers. On the other hand, when the adhesive is not modeled in the intermediate layer, it has been observed that the CPU time is reduced by 2 times while the results are seen small changes.

\section{Introduction}

Sheet metals are frequently used in products produced by deep drawing method such as kitchen utensils, medical storage boxes and automobile bodies. In places where willing high strength and lightness, multi layer sheets are preferred instead of single sheets. Layered sheets are divided into 3 main groups as metal / metal, metal / polymer / metal and metal / composite / metal. Bimetallic sheets are a layered sheet obtained by combining two different sheet metals with methods such as welding, bonding, rolling or hot pressing. With using different metals, a composite sheet has different properties and thicknesses can be obtained with superior properties of each sheets. In this way, lighter, corrosion-resistant, highstrength materials can be obtained. It is especially preferred in sectors where material lightness is at the forefront for energy saving such as automotive industry.

Deep drawing is basically the process of drawing sheet metal into the die with the help of a punch. This manufacturing technique is a frequently used method in productions made with bimetallic sheets. However, problems such as separation between layers, wrinkling and tearing are encountered in products produced by this method. There are different studies in the literature investigating these problems. For example, Mori and Kurimoto [1] examined the formability and wrinkling behavior of the sheets with the press-forming tests of pressure welded hot rolled stainless steel - aluminum sheets. As a result, they observed that the formability of the bimetallic sheet in stretching and deep drawing processes is better when the steel layer comes into contact with the punch. They also stated that the wrinkling state during deep drawing is controlled by the harder stainless steel. Chen et al. [2] investigated the earing behavior of Al / Cu bimetallic sheet during cylindrical deep drawing. They bonded aluminum and copper sheets by cold rolling. Afterwards, they determined the level and change of earing by subjecting the sheets they annealed at different temperatures to deep drawing process. Morovvati et al. [3] investigated the required blank holder force (BHF) to prevent wrinkling in deep drawing of an adhesive bonded aluminum / steel bimetallic sheet. As a result, they showed that the BHF required to prevent wrinkling in the layered sheets consisting of high and low strength sheets is at a value between the BHFs required for each layer. In another study, Aghchai et al. [4] examined the effect of the mechanical properties of materials on the formability of Al3004 / St12 bimetallic sheet. The proposed theoretical model showed that the forming 
limit curve (FLC) of laminated sheet is between the FLCs of the constituent materials. Afshin and Kadkhodayan [5] investigated the effects of different factors such as temperature, grain size, BHF, layer alignment and friction on the deep drawing process of Al 1050 / St 304 and Al 5052 / St 304 bimetallic sheets. As a result, they determined that the damage occurred in the areas of the punch radius and cup walls. In addition, they found that the punch force was less if the steel layer was on the upper side than when the aluminum layer was on the upper side.

Finite element (FE) analysis is using for predict the problems encountered in deep drawing processes. Experiments in many studies have been supported by FE analysis. In the analysis of bimetallic sheets, it is very important to use the model that gives the most realistic result in the shortest time. Bimetallic sheets have been modeled with many different assumptions in the literature. Takuda et al. [6] simulated the deep drawing process of the St / Al bimetallic sheet. They neglected the resin layer in the FE model of the sheets and bonded with polyurethane resin. Therefore, the resin layer was not modeled and it was accepted that there was no slippage between the layers. Parsa et al. [7] investigated numerically and experimentally the effect of thickness ratio and layer sequence on the drawing ratio that can be obtained in deep drawing of aluminum / stainless steel bimetallic sheets. They accepted that there is no slippage between layers in the models created axisymmetrically. Bagherzadeh et al. [8] modeled the hydromechanical deep drawing (HMDD) process of St/Al bimetallic sheets using finite element method (FEM). St-Al bimetallic sheet were laminated by a polyurethane base adhesive. Similar to previous studies, they modeled bimetallic sheet as two different layers, but made the assumption that there was no slippage between layers.

Marandi et al. [9] investigated bulge test of Al-Cu bimetallic sheets using FEM and confirmed it by experimental test. Al-Cu bimetallic sheets were manufactured by explosive welding method. They assumed that layers in common interface were sticking firmly to each other and any slip or separation did not occur between layers while subjecting stresses and deformation. In the light of this assumption, each layer was modelled separately and then layers were bonded to each other with tie constraint. Simulation results of their study showed similarity with the experimental results. Sakhtemanian et al. [10] carried out the influences of some process prameters on bimetallic sheets' incremental forming, such as layers' arrangement, forming load, surface finish. Titanium and low-carbon steel sheet were connected to each other by explosive welding method. They validated the FE results using experimental data. In their study, the shell element was used for meshing the blank and they assumed that the sheets were perfectly bonded. To simulate the bimetallic sheet, one section was defined for each layer and the material properties of each sheet were attributed to each section. Then both sections were attached to each other using tie constraint. Thereby, no slippage permitted between layers. Karajibani et al. [11] also used same modelling method for AL-Cu bimetallic sheet. As in previous studies, they fabricated the bimetallic sheets using explosive welding.

Tseng et al. [12] experimentally investigated the formability of aluminum / copper bimetallic sheets manufactured with roll bonding in different thickness ratios with FE simulation. In the models they created, they modeled bimetallic sheet as a single sheet. They determined the material properties with the 
tensile tests made on the laminated sheets. In another study, Morovvati et al. [3] investigated the BHF required to prevent wrinkling in deep drawing of $\mathrm{Al} / \mathrm{St}$ bimetallic sheet bonded with polyurethane adhesive. By modeling the polyurethane interlayer in the FE model of the sheets, they accepted that this layer adheres tightly to the aluminum and steel layers and that there is no slippage and separation between the layers.

Nejad et al. [13] modeled the study, which was previously performed experimentally by Atrian and Fereshteh-Saniee [14], with the Abaqus finite element program. After determining that the models were compatible with the experimental results, they analyzed the effects of punch radius, die radius, friction coefficients of steel and brass layers on surfaces, BHF and sheet diameter on punch force and thickness reduction statistically with response surface method. While modeling bimetallic sheets, they accepted the presence of Columb friction between layers. Therefore, they created a model that allows sliding and separation between layers. They determined the average friction coefficient of steel and aluminum sheets as the friction coefficient between these two layers.

Liu and Xue [15] experimentally examined the formability of AA5052 / polyethylene / AA5052 sandwich plates in their study. They prepared three kinds of AA5052 / polyethylene / AA5052 sandwich samples with different thicknesses of core material by hot pressing bonding method. They compared the FLC determined experimentally with the results of FE analysis. In the model created in their study, all metal and polymer layers are modeled. The inter-layer contact state is defined by Cohesive Zone Model (CZM). In their later work, they examined the deep drawing behavior of the same sheets. In their studies, which they supported with the FEM, they continued to use the CZM [16].

In this study, St / Al bimetallic sheets are modeled with the assumptions used in the above studies and different assumptions in addition to these, and the most suitable model type for bimetallic sheets is tried to be determined. For this purpose, T-peel test and Single Lap Joint test were performed to determine the peel resistance and shear strength of the samples. These tests are modeled in the ABAQUS FE program and the CZM parameters are determined. Then, by using 5 different models with the determined parameters, the behavior of the bimetallic sheets in the deep drawing process was simulated. The simulation results are compared with the experimental results and the optimum model type that gives the most realistic result in the shortest time is determined.

\section{Material}

In this study, steel and aluminum sheets were selected to create bimetallic sheet. Low carbon cold rolled steel sheet (DC01) suitable for deep drawing is used in the steel layer. This sheet metal is used in many places such as household items, refrigerators, washing machines, automotive industry, office supplies and lighting equipment. In the aluminium layer, EN AW $5754 \mathrm{H} 111$ aluminium-magnesium alloy sheet is used. This sheet has a harder structure than pure aluminium. Its corrosion resistance is high as well as welding ability is very good. In addition, it has high fatigue strength and is suitable for cold forming and 
coating. The chemical contents offered by the companies belonging to steel and aluminium sheets are given in Table 1.

Table 1

Chemical composition of steel and aluminium sheets

\begin{tabular}{|lllllllll|}
\hline Materials & $\% \mathrm{C}$ & $\% \mathrm{P}$ & \%S & \%Mn & $\% \mathrm{Si}$ & $\% \mathrm{Mg}$ & $\% \mathrm{Al}$ & $\% \mathrm{Fe}$ \\
\hline EN 10130 & 0.12 & 0.045 & 0.045 & 0.6 & - & - & - & 99.16 \\
\hline EN AW 5754 H111 & - & - & - & - & 0.42 & 3.16 & 96.42 & - \\
\hline
\end{tabular}

Bimetallic sheets used in experiments are combined with polyurethane resin. The properties of the polyurethane resin offered by the company are given in Table 2 . This adhesive can be used in different conditions and at different temperatures. It has high electrical resistance and dielectric coefficient. It is resistant to abrasion, acid and similar corrosive substances. It hardens at low temperatures without significant volume change. Curing time can be shortened thanks to catalysts. In the preliminary tests with epoxy and other silicon based adhesives, it was observed that these adhesives become brittle after curing. In the polyurethane resin, the structure formed after curing was determined to be ductile.

Table 2

Polyurethane resin adhesive properties

\begin{tabular}{|ll|}
\hline Properties & Value \\
\hline Density of adhesive & $1.43 \mathrm{~g} / \mathrm{cm}^{3}$ \\
\hline Density of hardener & $1.22 \mathrm{~g} / \mathrm{cm}^{3}$ \\
\hline Temperature resistance & $-45 /+280^{\circ} \mathrm{C}$ \\
\hline Shore hardness & $90-95$ \\
\hline Dielectric coefficient & $3.5 \mathrm{~F} / \mathrm{m}$ \\
\hline Application temperature & $5-35^{\circ} \mathrm{C}$ \\
\hline
\end{tabular}

Mechanical properties of sheet metals and resin used in the study were determined by tensile testing. Steel and aluminium specimens are prepared according to ASTM-E8 standard in the direction of rolling, diagonal and perpendicular to the direction of rolling. Tensile tests were carried out on Instron 5982 universal test device with a loading capacity of 10 tons. The true stress - true strain curves of sheet metal obtained as a result of tensile testing are given in Fig. 1. In addition, the mechanical properties of sheet metal are given in Table 3. 
Table 3

Mechanical properties of steel and aluminium sheets

\begin{tabular}{|lll|}
\hline Properties & DC01 & EN AW 5754 \\
\hline Elastic modulus, $\mathrm{E}(\mathrm{GPa})$ & 194.7 & 77.03 \\
\hline Yield stress, $\sigma_{0.2}(\mathrm{MPa})$ & 204.3 & 120.2 \\
\hline Tensile stress, $\sigma_{c}(\mathrm{MPa})$ & 335.9 & 237.5 \\
\hline Uniform elongation, $\varepsilon(\mathrm{mm} / \mathrm{mm})$ & 0.241 & 0.188 \\
\hline Max. elongation, $\varepsilon_{\mathrm{k}}(\mathrm{mm} / \mathrm{mm})$ & 0.406 & 0.204 \\
\hline Strain hardening exponent, $\mathrm{n}$ & 0.212 & 0.261 \\
\hline Strength coefficient, $\mathrm{K}(\mathrm{MPa})$ & 576.3 & 436.9 \\
\hline $\mathrm{R}_{0}$ & 1.962 & 0.942 \\
\hline $\mathrm{R}_{45}$ & 1.271 & 0.995 \\
\hline $\mathrm{R}_{90}$ & 2.600 & 0.846 \\
\hline Thickness, $\mathrm{t}(\mathrm{mm})$ & 0.5 & 1 \\
\hline
\end{tabular}

In the study, the adhesive used for joining the sheets was poured into molds prepared as dog-bone shape and after being cured completely, they were subjected to tensile testing. The sizes of the produced specimens are the same as sheet metal specimens. As a result of the tensile test, the true stress-true strain curve of the polyurethane resin is presented in Fig. 2.

\section{Methods}

\subsection{Bonding procedure}

Steel and aluminum sheets were laminated by a two-component polyurethane resin. Before the process, the surfaces of the sheet metals were sanded with 180 grid sandpaper and the surface was cleaned from oxide and similar residues. Then, the surface is wiped with ethyl alcohol, and cleaned from dirt such as oil and left to dry. Polyurethane resin prepared by adding a hardener in a ratio of 4 to 1 was applied to the surfaces. The adhered samples were left to dry for 24 hours.

\subsection{Experimental equipment}

Bimetallic sheets were deep drawn in a die set. The dimensions of the die set has given in Fig. 3. A double-acting hydraulic press with a loading capacity of 80 tons was used for this process. The circular specimens with a diameter of $90 \mathrm{~mm}$ were deep drawn by adjusting the blank holder force (BHF) to $53 \mathrm{kN}$ 
( 30 bar). During the process, punch force and displacement were recorded. Specimen thicknesses were measured after deep drawing process.

\section{Finite Element Models}

\subsection{Cohesive zone model}

In sheets combined with bonding, the adhesive applied to the interface attaches to the surface by establishing a bond with the sheet surface. Classical Columb friction is usually insufficient to define this situation. Because, different from the friction situation between the bimetallic sheets, the surfaces stick together. Adhesion has different strength depending on peeling and sliding situations, and when this strength is exceeded, the surfaces do not separate completely and gradually damage occurs and continues.

In order to simulate the bimetallic structure, Cohesive Zone Model (CZM) was used between the surfaces [17]. CZM uses the delamination that occurs against the tensile load to model the split on the interfaces. In other words, it takes into account the separation distance of the surfaces and the force applied to separate the adhered surfaces. Because the adhesive allows some elastic elongation, CZM accepts an elastic traction-seperation law between surfaces before damage. In case of exceeding this elastic limit, CZM assumes that the damage in the adhesive bond is caused by the gradual deterioration of the adhesive stiffness.

In the adhesive surface model, damage begins with a quadratic equation reaching the value " 1 ", which includes the adhesion stresses [18]. In Eq. (4.1), $\sigma_{1}, \sigma_{2}, \sigma_{3}$ show the stress in the normal, first and second shear directions, respectively. $\sigma_{1}{ }^{0}, \sigma_{2}{ }^{0}, \sigma_{3}{ }^{0}$ mean critical contact stresses in cases where the separation is only in the normal of the contact surface, only in the first and only the second shear direction, respectively.

$$
\left\{\frac{\left\langle\sigma_{1}\right\rangle}{\sigma_{1}^{\circ}}\right\}^{2}+\left\{\frac{\left\langle\sigma_{2}\right\rangle}{\sigma_{2}^{\circ}}\right\}^{2}+\left\{\frac{\left\langle\sigma_{3}\right\rangle}{\sigma_{3}^{\circ}}\right\}^{2}=1
$$

The equation stated above only represents the initiation of the damage. However, after the damage initiates, it develops progressively. An energy statement is used in CZM to express the progress of the damage. The fracture energy that will occur on traction of adhering surfaces in both normal and cutting directions (mixed mode) can be defined by a power law. Thanks to this power law (Eq. 2), failure under mixed mode can be expressed as the sum of the energies required for failure caused by individual modes (normal or shear mode). In Eq. 2, $G_{1}, G_{2}$, and $G_{3}$ represent the Griffith fracture energy required for separation in the first, second shear and normal direction, respectively. $G_{1}{ }^{C}, G_{2}{ }^{C}$, and $G_{3}{ }^{C}$ express the critical fracture energies required for failure in the normal, the first and the second shear directions, respectively. 


$$
\left\{\frac{G_{1}}{G_{1}^{C}}\right\}+\left\{\frac{G_{2}}{G_{2}^{C}}\right\}+\left\{\frac{G_{3}}{G_{3}^{C}}\right\}=1
$$

In ABAQUS finite element program, $\sigma_{1}{ }^{0}, \sigma_{2}{ }^{0}, \sigma_{3}{ }^{0}, G_{1}{ }^{C}, G_{2}{ }^{C}$, and $G_{3}{ }^{C}$ values must be given as input to model CZM. $\sigma_{3}{ }^{0}$ ve $G_{3}{ }^{C}$ values, which are in the normal direction from these values, are determined by T-peel test and $\sigma_{1}{ }^{0}, \sigma_{2}{ }^{0}, G_{1}{ }^{C}$, ve $G_{2}{ }^{C}$ values are in the shear direction and determined by single-effect connection test.

\subsubsection{T-peel test model}

T-peel test is a test performed to determine the strength of the adhesive in the surface normal direction [19]. The test sample is obtained by bonding two L-shaped sheet metal together with an adhesive to form a T-shape. This specimen is then tested by pulling it perpendicular to the adhesion surface. In this study, the experimental T-peeling test was modelled with the ABAQUS and the input parameters of the adhesion were determined. The adhesive behaviour between the two surfaces can be simulated by the CZM. The mechanical properties of the adhesive in the normal direction $\left(\sigma_{3}{ }^{0}\right.$ and $\left.G_{3}{ }^{9}\right)$ were determined by the T-peel test.

T-peel test sample is given in Fig. 4a and FE model is given in Fig. 4b. Aluminium is modelled on the upper layer, steel sheet on the lower layer and $0.2 \mathrm{~mm}$ thick adhesive material on the intermediate layer. CZM is defined between the intermediate layer and metal surfaces (aluminium and steel sheets). CPE4R element type with 4 nodes is used for all elements in the model. The mesh size is kept too small ( $0.1 \mathrm{~mm}$ ) to provide a solution. Each layer has 3 layers of mesh throughout the thickness. The total number of mesh elements in the model is 5667. The loop in Fig. 5 has been used to determine the CZM parameters [20].

In Fig. 6, simulation results obtained from FE model are compared with experimental datas. According to the latest estimate made by the program, the curve obtained was close to the experimental curve. Accordingly, the maximum stress required for the onset of damage in the normal direction was determined as 3.8 MPa. The energy required to cause the failure is determined as $1000 \mathrm{~J} / \mathrm{m}^{2}$.

\subsubsection{Single lap joint model}

Single lap joint test is a standard test method using for determine the shear strength of adhesion [21]. Standart test specimen is given in Fig. 7a. The single lap joint test was modeled with FEM (Fig. 7b). 4node CPE4R element type was used in the model. Mesh size is $0.05 \mathrm{~mm}$ and the model has 673 mesh elements. CZM parameters in the shear directions were determined by using the same loop as the T-peel.

Experimental and FEM results of single lap joint test are given in Fig. 8. The maximum stress value that gives the closest output to the experimental data is $3.2 \mathrm{MPa}$ and fracture energy value is $820 \mathrm{~J} / \mathrm{m}^{2}$. CZM parameters estimated by FEM are given in Table 4. 
Table 4

CZM parameters

\begin{tabular}{|llllll|}
\hline $\boldsymbol{\sigma}_{1}{ }^{0}$ & $\boldsymbol{\sigma}_{2}{ }^{0}$ & $\boldsymbol{\sigma}_{3}{ }^{0}$ & $\mathbf{G}_{1}{ }^{\mathrm{C}}$ & $\mathbf{G}_{2}{ }^{\mathrm{C}}$ & $\mathbf{G}_{3}{ }^{\mathrm{C}}$ \\
\hline $3.2 \mathrm{MPa}$ & $3.2 \mathrm{MPa}$ & $3.8 \mathrm{MPa}$ & $820 \mathrm{~J} / \mathrm{m}^{2}$ & $820 \mathrm{~J} / \mathrm{m}^{2}$ & $1000 \mathrm{~J} / \mathrm{m}^{2}$ \\
\hline
\end{tabular}

\subsection{Bimetallic sheet models}

In bimetallic sheets, two different metallic materials are combined with an adhesive. The adhesive applied to the sheet metal surface solidifies after the process and adhesion occurs between the solidified adhesive and the sheet metal. From this point, FE models of bimetallic sheets can be modelled by making different assumptions. In Fig. 9, five different models used in FE analysis of bimetallic sheets formed by bonding are given.

\section{Model-A}

This model is the closest model to the real situation. The adhesive that solidifies between the sheet metal is considered a separate layer. CZM is defined between this layer and the sheet metal surface (Fig. 9a). If the adhesion force is exceeded during forming, separation may occur between the surfaces. In some studies in the literature, layered sheets are modeled in this way $[16,18]$.

\section{Model-B}

In this model, it is accepted that there is an excellent adhesion between sheet metal and solidified adhesive (Fig. 9b). The sheet metal is considered as a whole and is split into three parts to identify different materials. No contact condition has been defined on the interface. No separation is observed during forming.

\section{Model-C}

In this model, CZM is defined between sheet metals (Fig. 9c). The solidified adhesive is not modelled as a layer. If the adhesion force is exceeded during forming, separation may occur between the surfaces.

\section{Model-D}

In this model, adhesion is assumed to be perfect (Fig. 9d). The adhesive between sheet metals has been neglected. Sheets are modelled as in Model-B but the middle layer is not modelled. No contact condition has been identified on the interface. No separation is observed during forming. Bagherzadeh et al. [8] and Atrian and Fereshteh-Saniee [14] modelled the layered sheets in this way.

\section{Model-E}

This model is modeled similarly to Model-C (Fig. 9e). However, Columb friction is defined between layers instead of CZM [13]. As the coefficient of friction between steel and aluminum sheets, the average value 
of the friction coefficients between sheets and dies was used. There may be slippage and separation between layers during forming.

Deep drawing simulations were carried out with the different models described above. By comparing the results obtained from these models with the experimental results, the model that gives the most realistic result was determined.

\section{Results And Discussion}

\subsection{Strain Distribution}

Thickness measurements were made at 6 different points on the test sample (Fig. 10) and the curve graph through these points was drawn. In simulations made with Model-A, Model-B, Model-C, Model-D and Model-E, the thickness change in the aluminum layer was compared with the experimental results (Fig. 11). In the simulation results, the change in thickness across the section is given. It was observed that the thickness became thinner at the base of the cup $(0-15 \mathrm{~mm})$. This thinning has increased in the area of the punch radius. It has been determined that the thickness of the cup wall increases with distance from the punch radius.

In Fig. 11, it can seen that the thickness changes of Model-A and Model-C are similar. On the other hand, a similarity was observed in thickness changes between Model-B and Model-D. In the punch radius section (15-25 mm), all models show similar thickness changes, while the models show two different trends in the cup walls. Model-B and Model-D are extremely thinning from the punch radius to the middle of the cup wall, while Model-A, Model-C and Model-D begin to thicken along the mug height after some thinning. The common feature of these three models is that sliding and separation between layers are allowed. This prevented the excessive thinning of the cup walls.

The results obtained from the aluminum layer of the test sample are matched with the results from the same points in the simulation (Fig. 12). Experimental data and simulation data were transferred to a graph and the trend lines fitted to this data. The slope of the fitted lines and the determination coefficients of the lines have given in Table 5. As the slope of the line approaches 1, the similarity between the experimental results and the simulation results increases. However, the slope of the line is not enough itself. The determination coefficient shows how close the points are to the line. In other words, it shows how the line is compatible with the data. Therefore, as the determination coefficient approaches 1 , the accuracy of the simulation results will increase. It is seen in Fig. 12 that the highest determination coefficient is in Model-A. In addition, it has been observed that the slope value of the line fitted to Model-A is close to 1 . On the other hand, although Model-C has similar results with Model-A, the determination coefficient of Model-C is lower. 
Table 5

Slope and determination coefficient of trend lines

of Al layer

\begin{tabular}{|lll|}
\hline Model & Slope & Determination Coefficient \\
\hline Model-A & 1.061 & 0.9825 \\
\hline Model-B & 0.9457 & 0.9309 \\
\hline Model-C & 1.0513 & 0.9757 \\
\hline Model-D & 0.7578 & 0.9325 \\
\hline Model-E & 1.2056 & 0.9846 \\
\hline
\end{tabular}

In Fig. 13, the thickness changes in the steel layer of the bimetallic sheet are compared with the thickness changes of the test sample. While the thickness decreased at the bottom of the cup, the thinning increased in the starting and ending $(20-30 \mathrm{~mm})$ parts of the punch radius. It was observed that sheet metal thickened on the walls of the mug with increasing cup height. Unlike the aluminum layer, a significant thinning was detected at the end of the punch radius in the test sample. Since the steel layer remains above the neutral axis, the thinning in this region is more than aluminum.

The differences between FEM models for the steel layer are more pronounced in terms of thickness variation. Model-A and Model-C have similar curves, while Model-B and Model-D have similar curves. On the other hand, Model-E is similar to Model-A and Model-C in the punch radius area, and Model-B and Model-D at the cup walls. In Fig. 14, the thickness changes taken in the steel layer of the test sample and the results obtained from the simulations was given comparatively. The slopes of the trend lines and their determination coefficients was given in Table 6. It can be seen from the determination coefficients that the datas are generally dispersed. The highest determination coefficient was obtained with Model-A. Although Model-B and Model-D slopes are close to 1, determination coefficients remained quite low. On the other hand, although Model-C's slope is higher, the coefficient of determination remained lower than Model-A. Model-E is the model with the lowest slope and determination coefficient.

Table 6

Slope and determination coefficient of trend lines of St layer

\begin{tabular}{|lll|}
\hline Model & Slope & Determination Coefficient \\
\hline Model-A & 0.8201 & 0.8351 \\
\hline Model-B & 1.0154 & 0.6986 \\
\hline Model-C & 0.8262 & 0.8016 \\
\hline Model-D & 1.0577 & 0.7306 \\
\hline Model-E & 0.6936 & 0.6333 \\
\hline
\end{tabular}


It is seen that the thickness variations are more in Model-B and Model-D in both layers. Because in these models, sliding and separation between layers was not allowed. Since there is no slipping between the surfaces, both layers move together and try to elongate equally during the deep drawing process. These elongations on the plane cause more deformation in the direction of thickness according to the constant volume rule. Since sliding between layers is possible in models created with CZM, steel layer becomes thinner and flows into the die. This situation is already evident from the earing situations after the procedure. While there are different ear heights between the layers in models created with CZM, in other models, the ears are equal in both layers.

\subsection{Punch force}

Force-displacement curves during deep drawing was given in Fig. 15. The simulation results made with 5 different models are similar. Error rates between maximum punch forces was given in Table 7.

Accordingly, although the experimental punch force curve was verified with all models, the lowest error rate for the maximum punch force was obtained with Model-C. However, other models have produced similar results. Some fluctuations occur in the punch force values in the simulation results. The cause of the fluctuation in the punch force-displacement curve observed in the simulation is the oscillation of the nodes in contact with the punch.

Table 7

Max. punch forces and error ratio

\begin{tabular}{|lll|}
\hline Model & Max. Punch Force (kN) & Error \\
\hline Model-A & 60.5 & $10 \%$ \\
\hline Model-B & 62.3 & $14 \%$ \\
\hline Model-C & 58.9 & $8 \%$ \\
\hline Model-D & 59.7 & $9 \%$ \\
\hline Model-E & 58.0 & $6 \%$ \\
\hline Experimental & $54.7 \pm 1$ & - \\
\hline
\end{tabular}

\subsection{Solution Times}

CPU time for each of the simulations performed with different models was given in Fig. 16. These values were obtained with a PC with Intel Core i7-4930K CPU $3.40 \mathrm{GHz}$ and $32 \mathrm{~GB}$ RAM. While the CPU time for Model $B$ and Model $D$ is around $20 \mathrm{~s}$, this value is around $60 \mathrm{~s}$ for Model A. In other words, while a fast solution is obtained with Models $B$ and $D$, Model $A$ has taken about 3 times more time to reach a solution. On the other hand, it can be seen that the CPU Time of Model C and Model E is around $30 \mathrm{~s}$. Model $\mathrm{C}$ is the optimum model type to obtain a fast and realistic solution considering the thickness changes and solution times.

\subsection{Strain Distribution of Different Models}


Strain distribution of different models after deep drawing is given in Fig. 17. The strain distribution of all models except Model $E$ are generally the same. In models with solidified adhesive in the intermediate layer, Model A and Model B, it is seen that the highest strain value is on adhesive. Due to low strength and elastic structure of the adhesive, the most of strain occurs in this region. Earing are seen in Models A, B, C and $D$. On the other hand, in model $E$, while the earing is seen in steel layer, it is not seen in the aluminum sheet. According to calculations after the tensile tests while aluminum has a low anisotropy coefficient in single sheets, the steel sheet has a higher anisotropy coefficient. Accordingly, since only friction is defined between layers in Model E, layers slipped on each other and layers did not interfere other layers during forming. In other four models, due to the strong adhesion between the layers, aluminum layer and steel layer moved together, resulting in a similar earing profile in both layers. It has been observed that in case of high adhesion in bimetallic sheets, a lower earing height was obtained compared to monolithic steel sheet.

\subsection{Effect of Solidified Adhesive Thickness}

The effect of the adhesive between the layers on the thickness of the sheet during deep drawing has been investigated. For this purpose, in addition to Model A and Model C, simulations were made for 0.4 and $0.6 \mathrm{~mm}$ adhesive thicknesses and thickness changes were analyzed. Thickness changes in Al and St layers are given in Fig. 18. The increase in the thickness of the adhesive generally had no effect on the change in thickness of the Al layer. On the other hand, when the St layer is analyzed, it can be seen that the thickness of the cup walls decreases with the increasing adhesive thickness. The causation of this is that the outer diameter of the cup increases with the increase of total sheet thickness and therefore more deformation in the outer layer.

\section{Conclusion}

In this study, the most accurate model was determined by comparing different simulation models used for bimetallic sheets. Within the scope of the study, five different models were created and outputs such as thickness changes, punch strength, CPU time were presented comparatively. Accordingly, the following results were obtained:

- When the sheet thicknesses are analyzed, the models that gives the most realistic results were determined as Model A and Model C. In both models, interlayer adhesion was defined by CZM. However, while the solidified adhesive in the middle layer was modeled in Model A, Model C did not have this layer.

- Although Model A and Model C gave similar results, the CPU time required for Model A was 2 times longer than that of Model C.

- The punch force-displacement curves were compatible with the experimental results for all models. While the maximum punch force was determined as $54.7 \mathrm{kN}$ in the experiments, Model E and Model C obtained the closest result with $6 \%$ and $8 \%$ error, respectively.

- Defining only Columb friction between layers in Model E took the model away from reality. Especially due to the anisotropic structure of the St layer, high earing occurred, while this did not occur in the Al 
layer. In other models, similar earing heights were observed by moving the Al and St layers together. In addition, it was observed that the earing heights were less than the monolithic St layer.

- The effect of adhesive thickness on sheet thickness in deep drawing of bimetallic sheets was investigated. It was observed that the sheet metal in the outer layer on the cup walls became thinner due to the increasing in the diameter of the cup as a result of the increase in adhesive thickness. It is concluded that this difference is negligible for the low adhesive thickness, so there is no need to model a solidified adhesive layer in the intermediate layer.

With this study, it was seen that the solidified adhesive does not need to be modeled as a separate layer in bimetalic sheets with low adhesive thickness $(<0.4 \mathrm{~mm})$. It has been determined that if the contact between layers is defined with CZM, more realistic results can be obtained. Considering the solution time, it has been determined that Model $\mathrm{C}$ is the most suitable model for modeling bimetallic sheets.

\section{Declarations}

Cengiz Görkem Dengiz: Conceptualization, Methodology, Investigation, Resources, Data Curation, Writing - Original Draft, Visualization, Software, Validation, Formal analysis

Kemal Yıldızlı: Writing - Review \& Editing, Supervision

Acknowledgements This study was fnancially supported by Turkish Council of Higher Education under scholar grad: ÖYP-1919-018, TUBITAK BIDEP 2211-A and Ondokuz Mayıs University Scientific Researched Project Department [grant number PYO.MUH.1905.16.002]. Special thanks to Mech. Eng. Gürkan Kara for his collaborations in this work.

\section{Declarations}

The authors have no conflicts of interest to declare that are relevant to the content of this article.

\section{References}

1. Mori T, Kurimoto S (1996) Press-formability of stainless steel and aluminum clad sheet. J Mater Process Technol 56:242-253

2. Chen C-Y, Kuo J-C, Chen H-L, Hwang W-S (2006) Experimental Investigation on Earing Behavior of Aluminum/Copper Bimetal Sheet. Mater Trans 47:2434-2443. https://doi.org/10.2320/matertrans.47.2434

3. Morovvati MR, Fatemi A, Sadighi M (2011) Experimental and finite element investigation on wrinkling of circular single layer and two-layer sheet metals in deep drawing process. Int J Adv Manuf Technol 54:113-121

4. Aghchai AJ, Shakeri M, Dariani BM (2013) Influences of material properties of components on formability of two-layer metallic sheets. Int J Adv Manuf Technol 66:809-823 
5. Afshin E, Kadkhodayan M (2015) An experimental investigation into the warm deep-drawing process on laminated sheets under various grain sizes. Mater Des 87:25-35.

https://doi.org/10.1016/j.matdes.2015.07.061

6. Takuda H, Mori K, Fujimoto H, Hatta N (1996) Prediction of forming limit in deep drawing of Fe/Al laminated composite sheets using ductile fracture criterion. J Mater Process Technol 60:291-296

7. Parsa MH, Yamaguchi K, Takakura N (2001) Redrawing analysis of aluminum-stainless-steel laminated sheet using FEM simulations and experiments. Int J Mech Sci 43:2331-2347. https://doi.org/http://dx.doi.org/10.1016/S0020-7403(01)00038-8

8. Bagherzadeh S, Mirnia MJ, Mollaei Dariani B (2015) Numerical and experimental investigations of hydro-mechanical deep drawing process of laminated aluminum/steel sheets. J Manuf Process 18:131-140. https://doi.org/10.1016/j.jmapro.2015.03.004

9. Marandi FA, Jabbari AH, Sedighi M, Hashemi R (2016) An Experimental, Analytical, and Numerical Investigation of Hydraulic Bulge Test in Two-Layer Al-Cu Sheets. J Manuf Sci Eng 139:031005. https://doi.org/10.1115/1.4034717

10. Sakhtemanian MR, Honarpisheh M, Amini S (2017) Numerical and experimental study on the layer arrangement in the incremental forming process of explosive-welded low-carbon steel/CP-titanium bimetal sheet. Int J Adv Manuf Technol 95:3781-3796. https://doi.org/10.1007/s00170-017-1462-z

11. Karajibani E, Hashemi R, Sedighi M (2017) Forming limit diagram of aluminum-copper two-layer sheets: numerical simulations and experimental verifications. Int J Adv Manuf Technol 90:27132722. https://doi.org/10.1007/s00170-016-9585-1

12. Tseng H-C, Hung C, Huang C-C (2010) An analysis of the formability of aluminum/copper clad metals with different thicknesses by the finite element method and experiment. Int $\mathrm{J}$ Adv Manuf Technol 49:1029-1036

13. Hasan Nejad SJ, Hasanzadeh R, Doniavi A, Modanloo V (2017) Finite element simulation analysis of laminated sheets in deep drawing process using response surface method. Int $\mathrm{J}$ Adv Manuf Technol 93:3245-3259. https://doi.org/10.1007/s00170-017-0780-5

14. Atrian A, Fereshteh-Saniee F (2013) Deep drawing process of steel/brass laminated sheets. Compos Part B Eng 47:75-81. https://doi.org/10.1016/j.compositesb.2012.10.023

15. Liu J, Xue W (2013) Formability of AA5052/polyethylene/AA5052 sandwich sheets. Trans Nonferrous Met Soc China 23:964-969. https://doi.org/http://dx.doi.org/10.1016/S10036326(13)62553-4

16. Liu J, Zhuang L (2018) Cylindrical cup-drawing characteristics of aluminum-polymer sandwich sheet. 1885-1896

17. Abaqus Manual (2007) Abaqus/explicit: user's examples and theory manuals. Dassault systemes

18. Liu J, Liu W, Xue W (2013) Forming limit diagram prediction of AA5052/polyethylene/AA5052 sandwich sheets. Mater Des 46:112-120.

https://doi.org/http://dx.doi.org/10.1016/j.matdes.2012.09.057

Page 15/30 
19. ASTM D1876-08 (2015) Standard Test Method for Peel Resistance of Adhesives (T-peel Test). ASTM International

20. Papazafeiropoulos G, Muñiz-Calvente M, Martínez-Pañeda E (2017) Abaqus2Matlab: A suitable tool for finite element post-processing. Adv Eng Softw 105:9-16. https://doi.org/10.1016/J.ADVENGSOFT.2017.01.006

21. ASTM D1002-10 (2005) Standard Test Method for Apparent Shear Strength of Single-Lap-Joint Adhesively Bonded Metal Specimens by Tension Loading (Metal-to-Metal). Standards 1-5. https://doi.org/10.1520/D1002-10.on

\section{Figures}

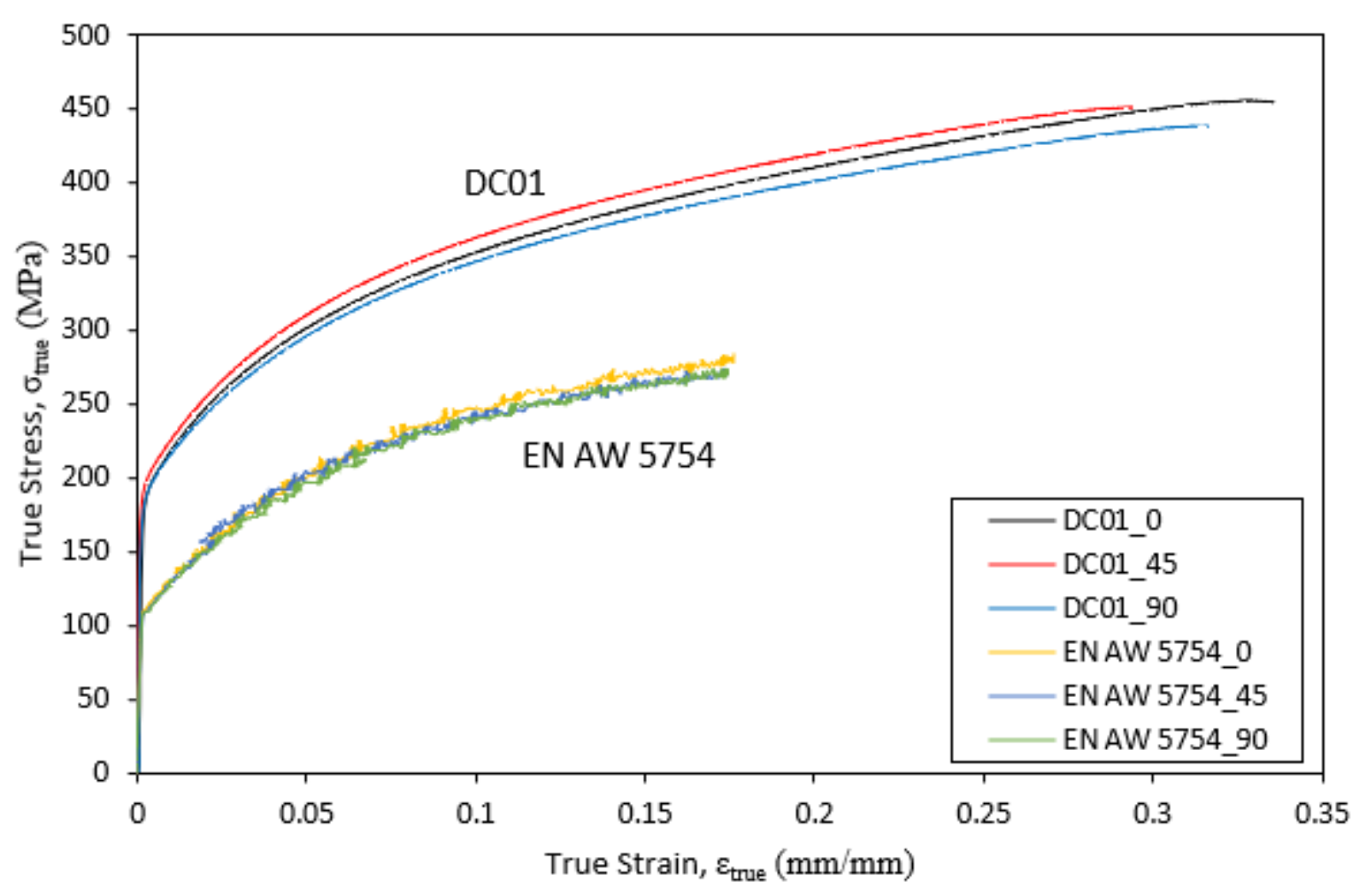

\section{Figure 1}

True stress- true strain diagram of steel and aluminium sheets 


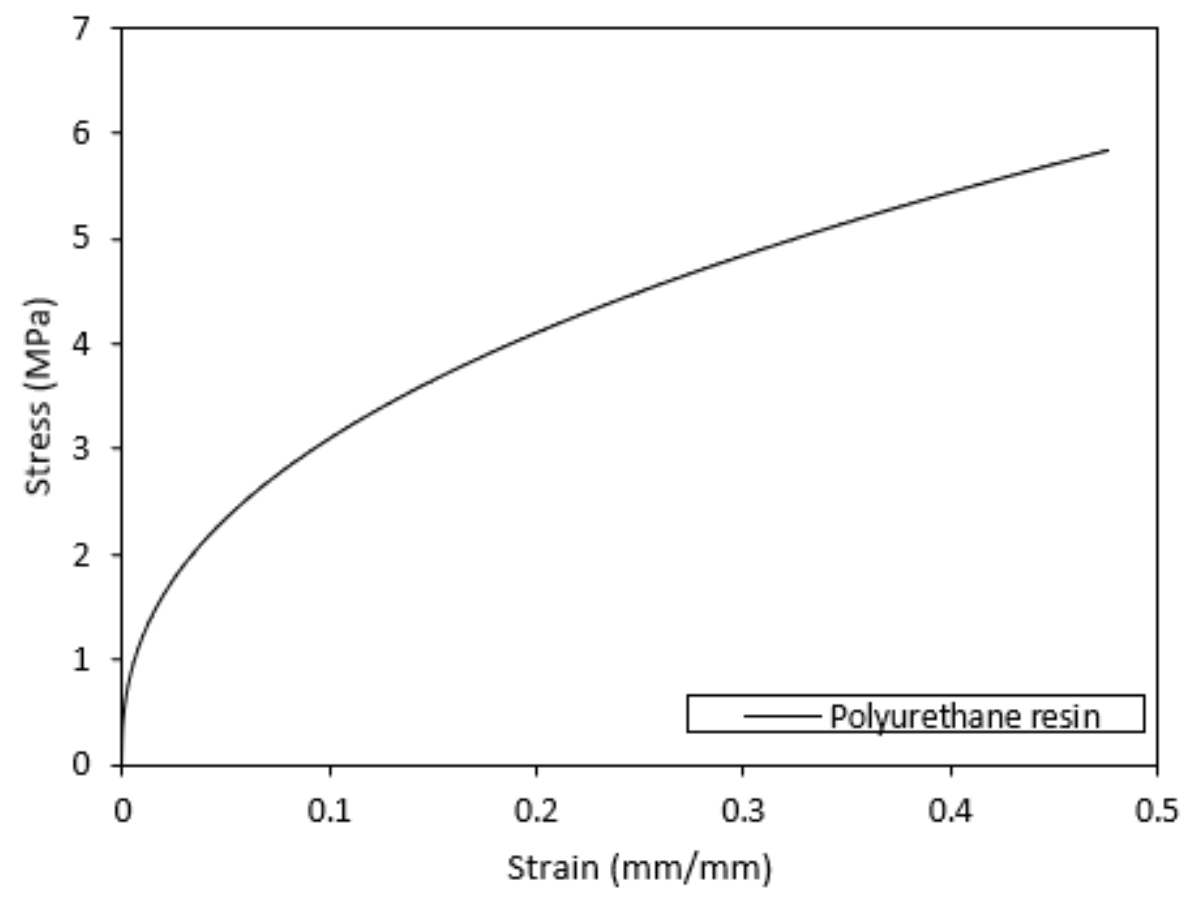

Figure 2

Stress-strain graphic of polyurethane resin.

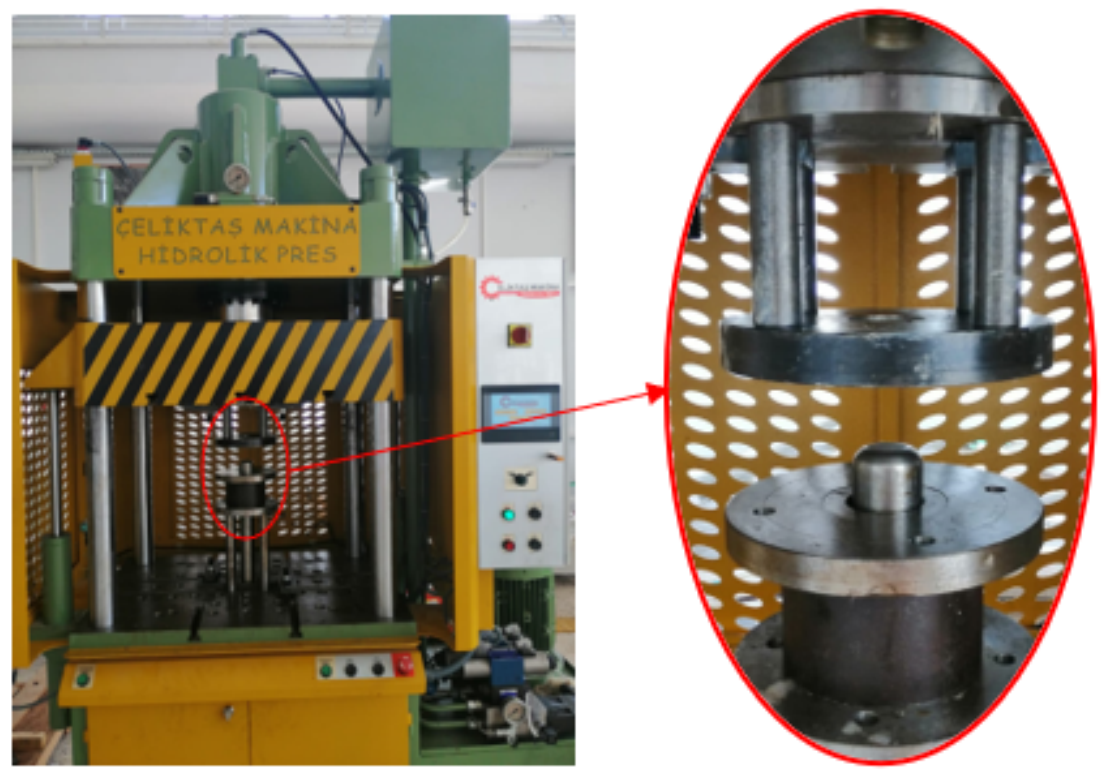

Figure 3

The view of the hydraulic press and die set. 


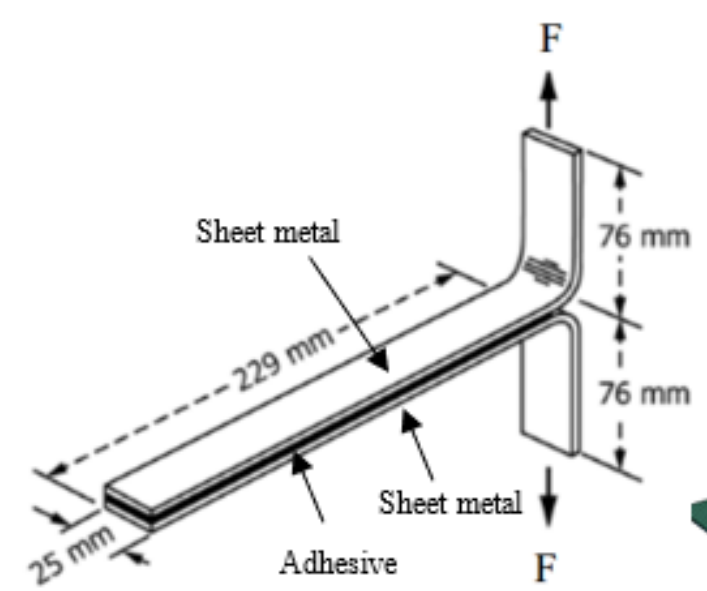

(a)

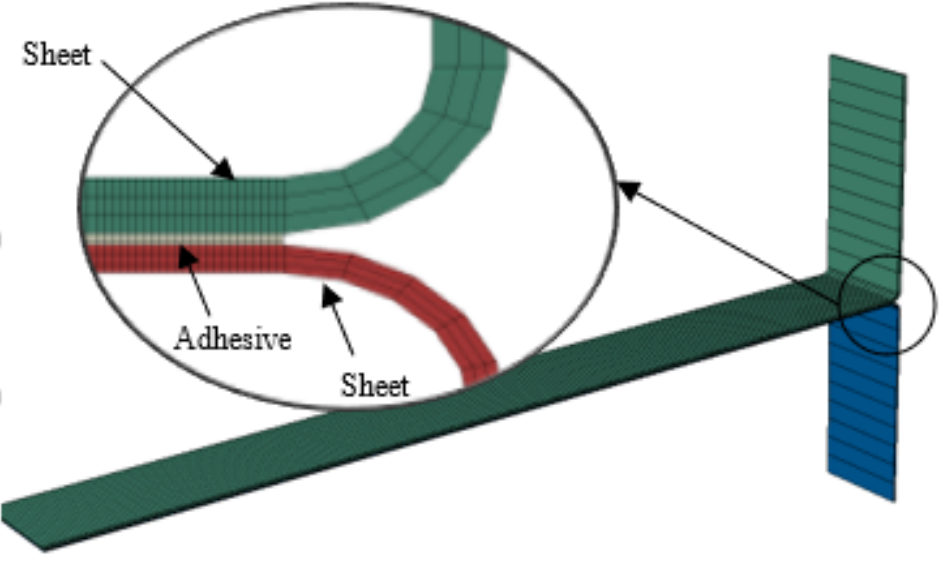

(b)

Figure 4

T-peel test (a) Schematic view (b) FE model 


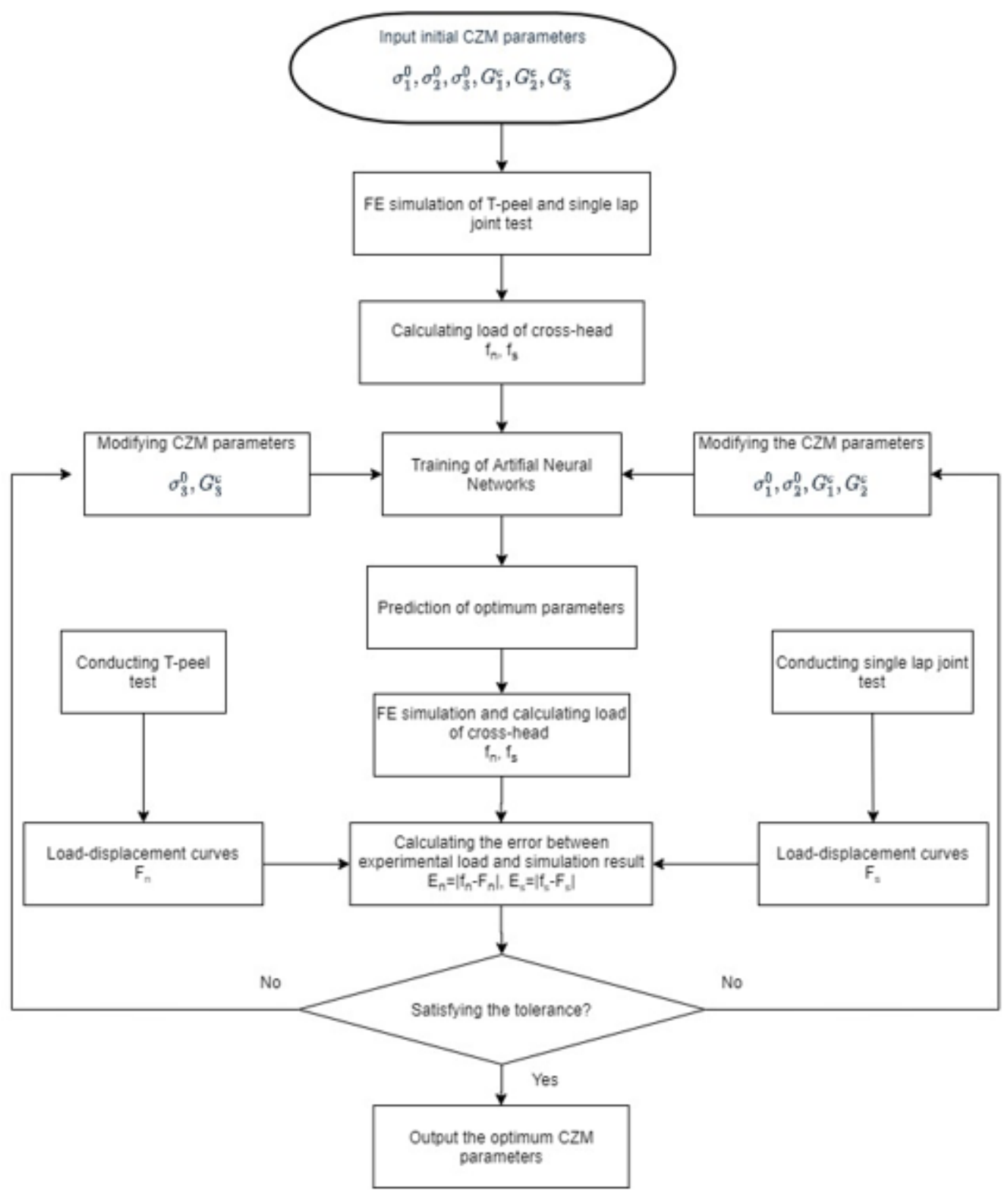

Figure 5

Flow chart of CZM parameter algorithm 


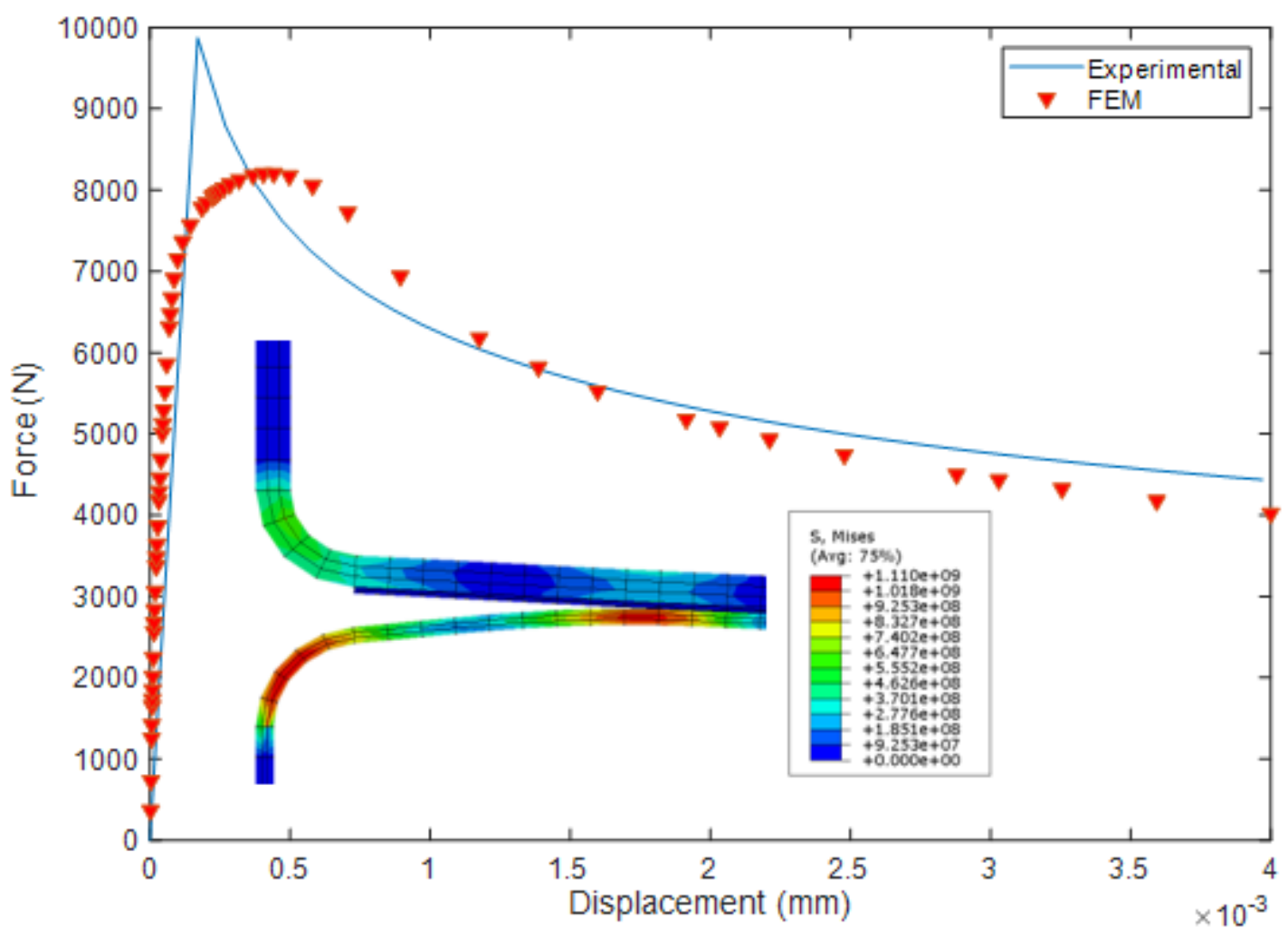

Figure 6

Experimental and simulated load-displacement curves of T-peel test 
Adhesive

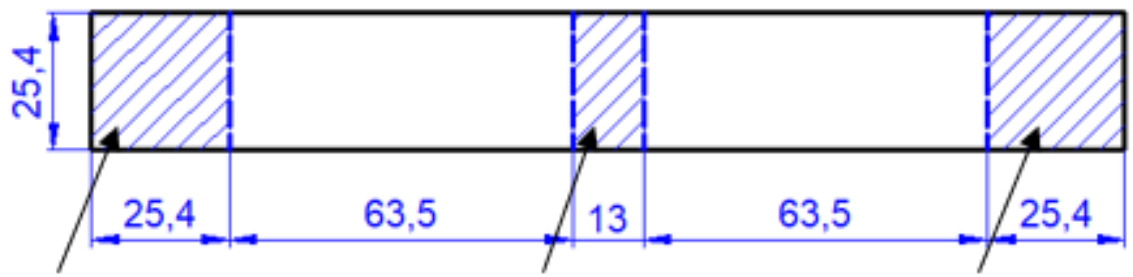

Grip zone

Shear area

Grip zone

(a)

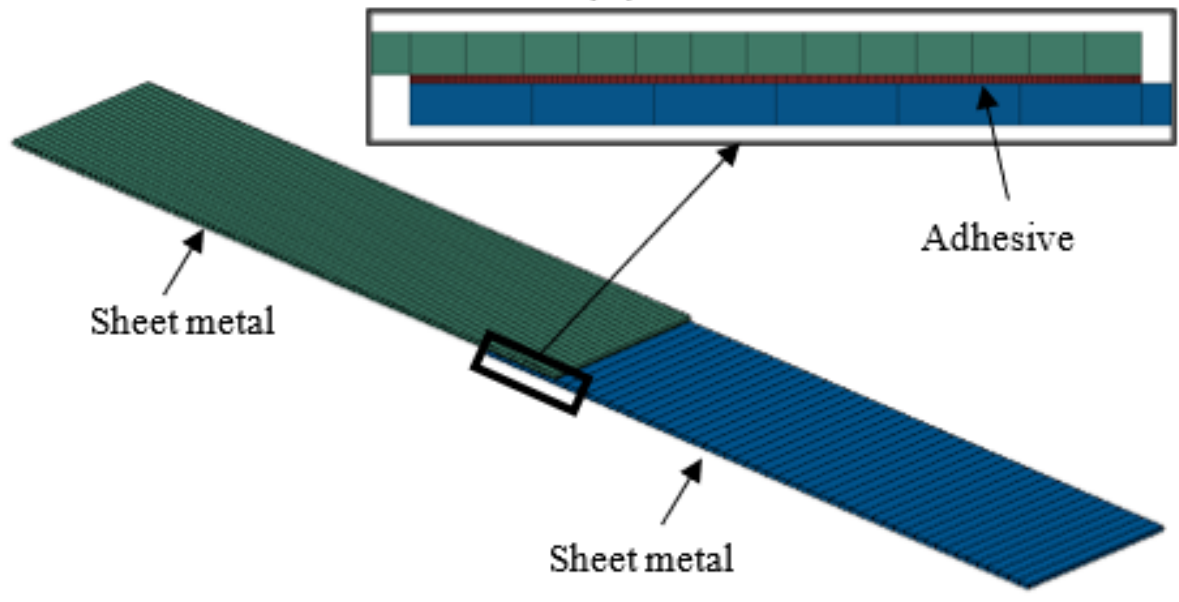

(b)

Figure 7

Single lap joint test (a) Schematic view (b) FE model 


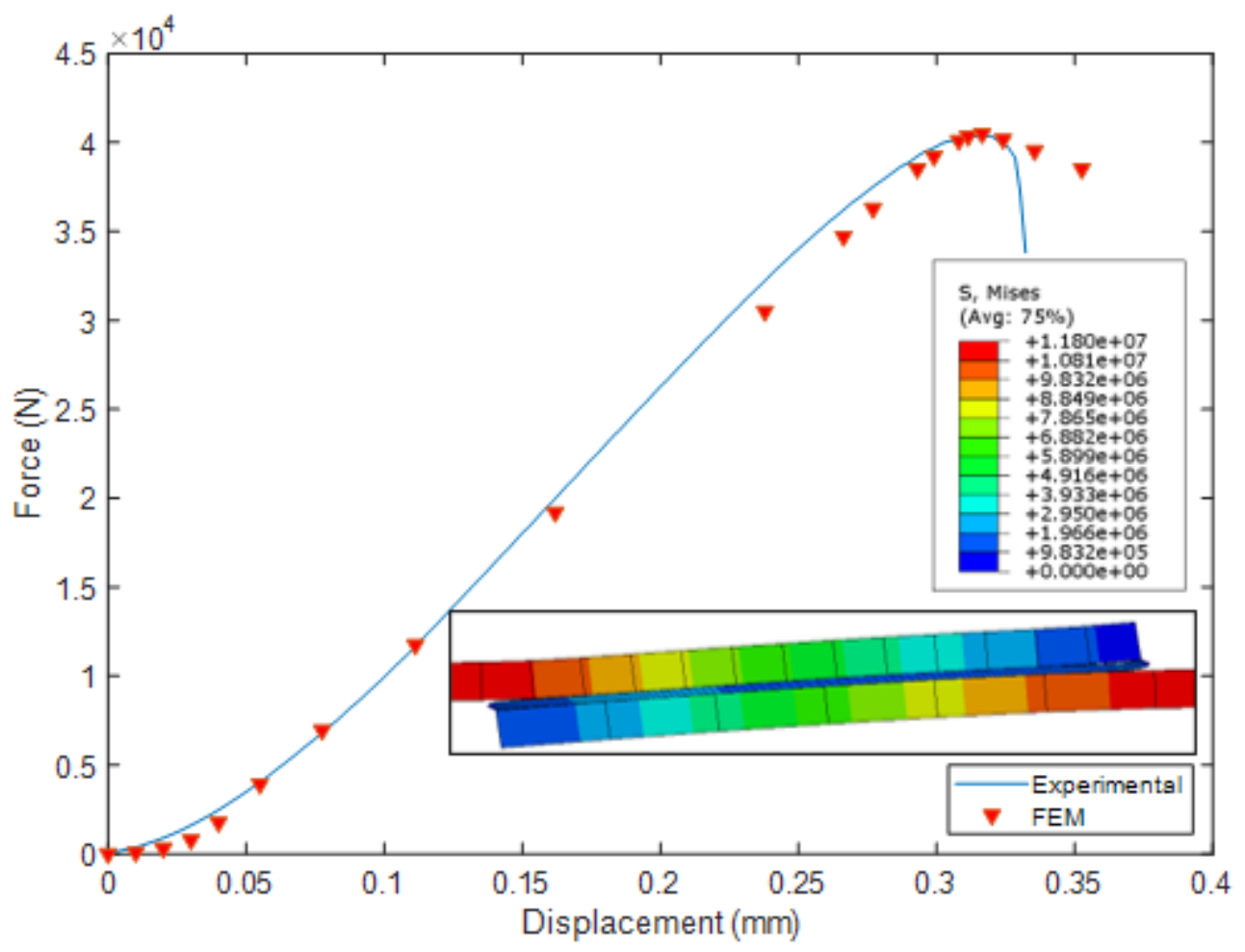

Figure 8

Experimental and simulated load-displacement curves of single lap joint test 
Solidified adhesive

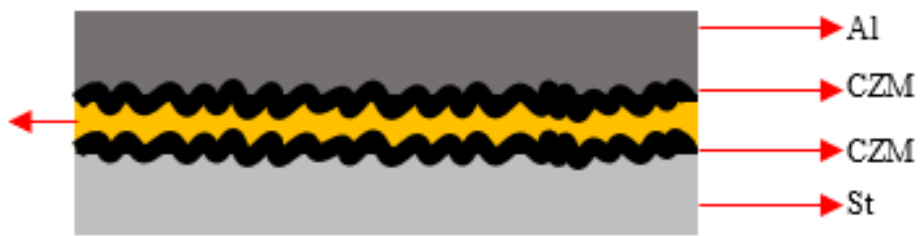

(a) Model A

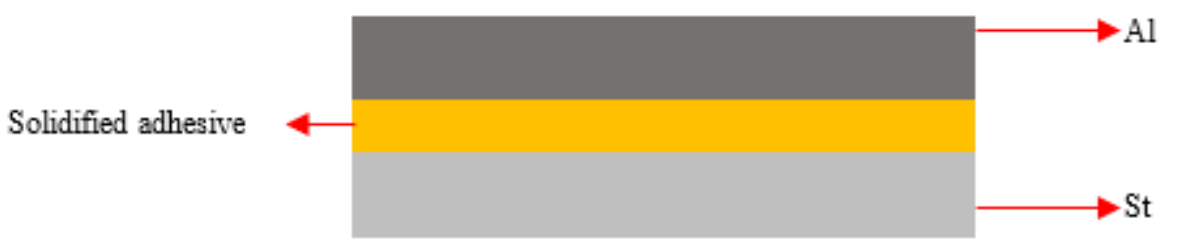

(b) Model B

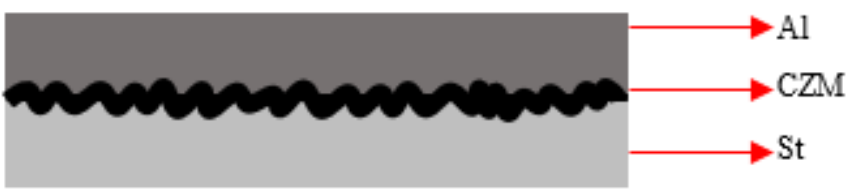

(c) Model C

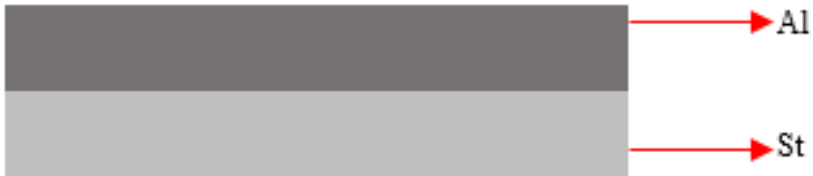

(d) Model D

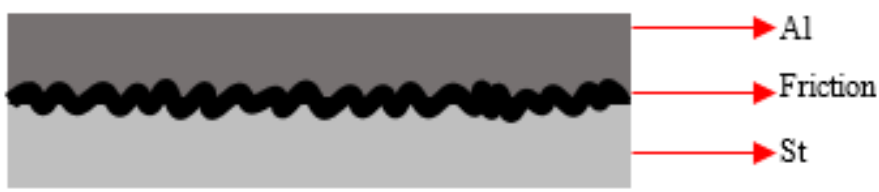

(e) Model E

\section{Figure 9}

Schematic view of bimetallic sheet model (a) Model-A (b) Model-B (c) Model-C (d) Model-D 


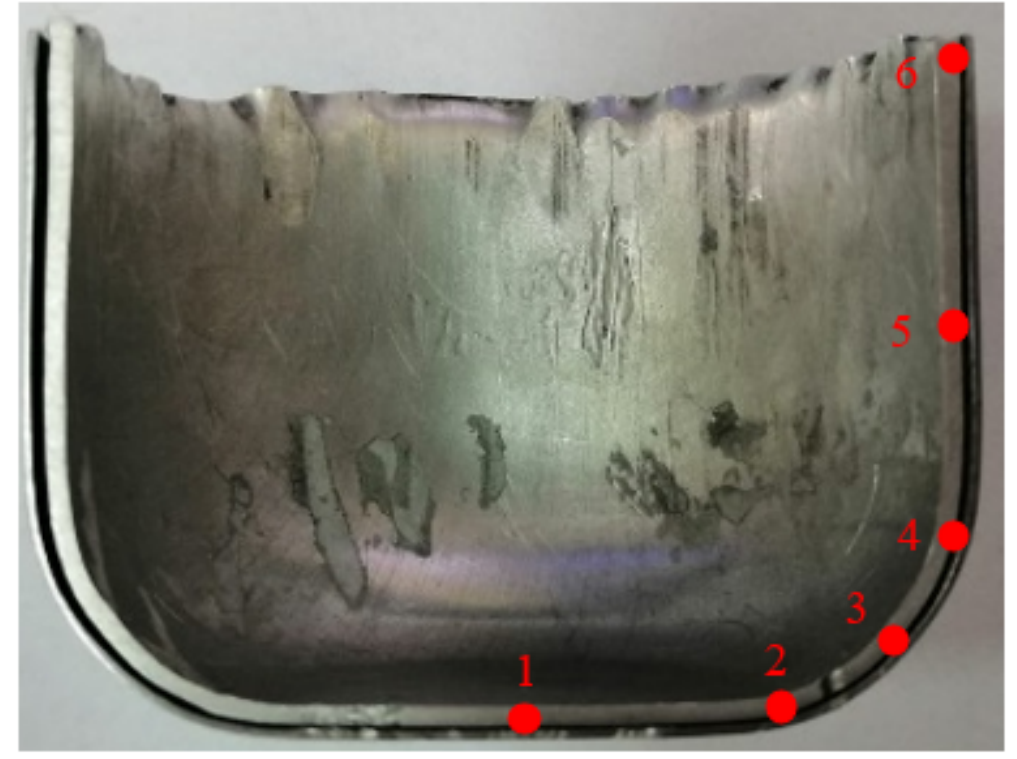

\section{Figure 10}

Thickness measurement points on deep drawn bimetalic sample.

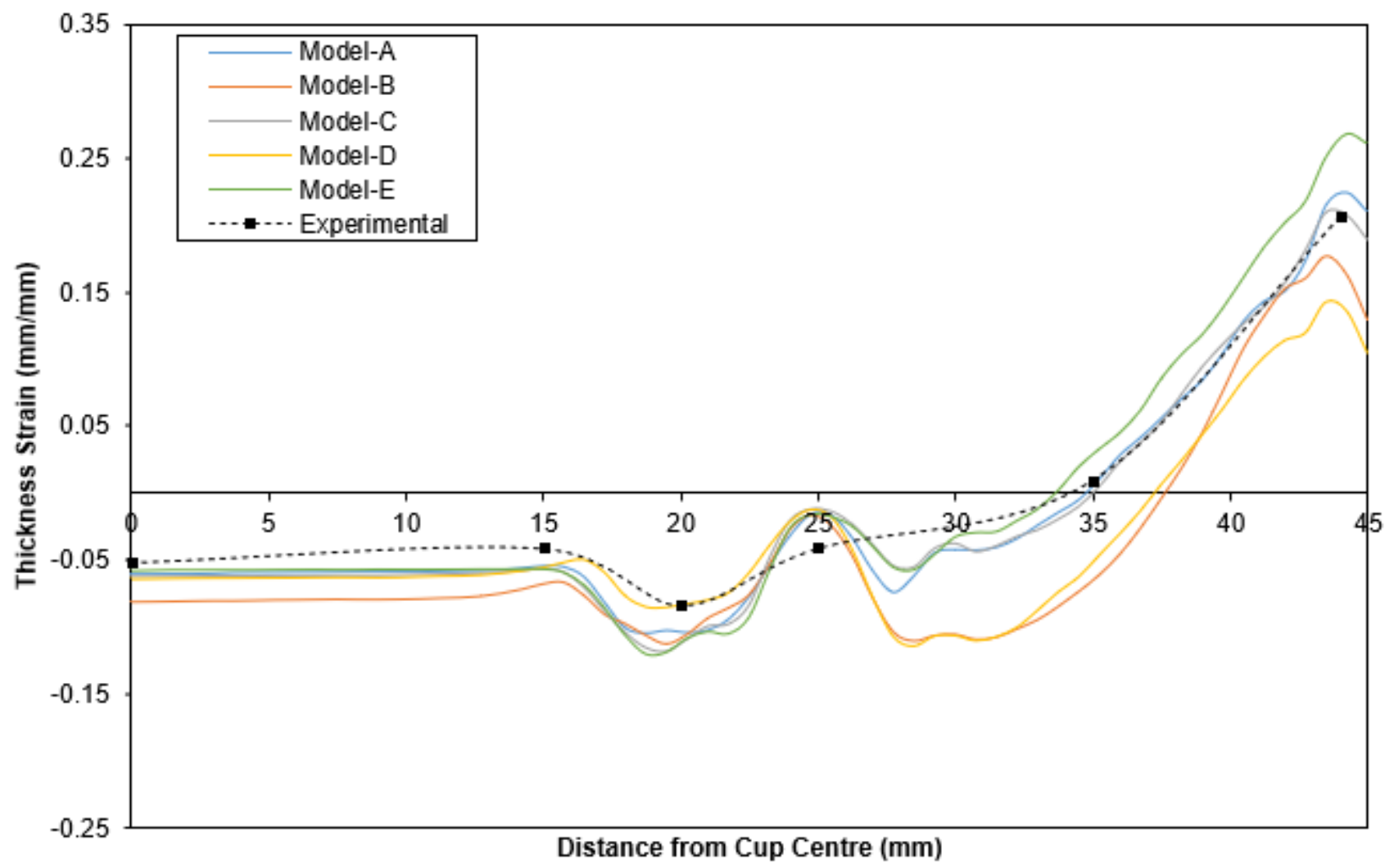

\section{Figure 11}

Comparison of the thickness strain on the Al layer of the bimetallic sheets created with Model-A, Model-B, Model-C, Model-D and Model-E in simulations with experimental results 


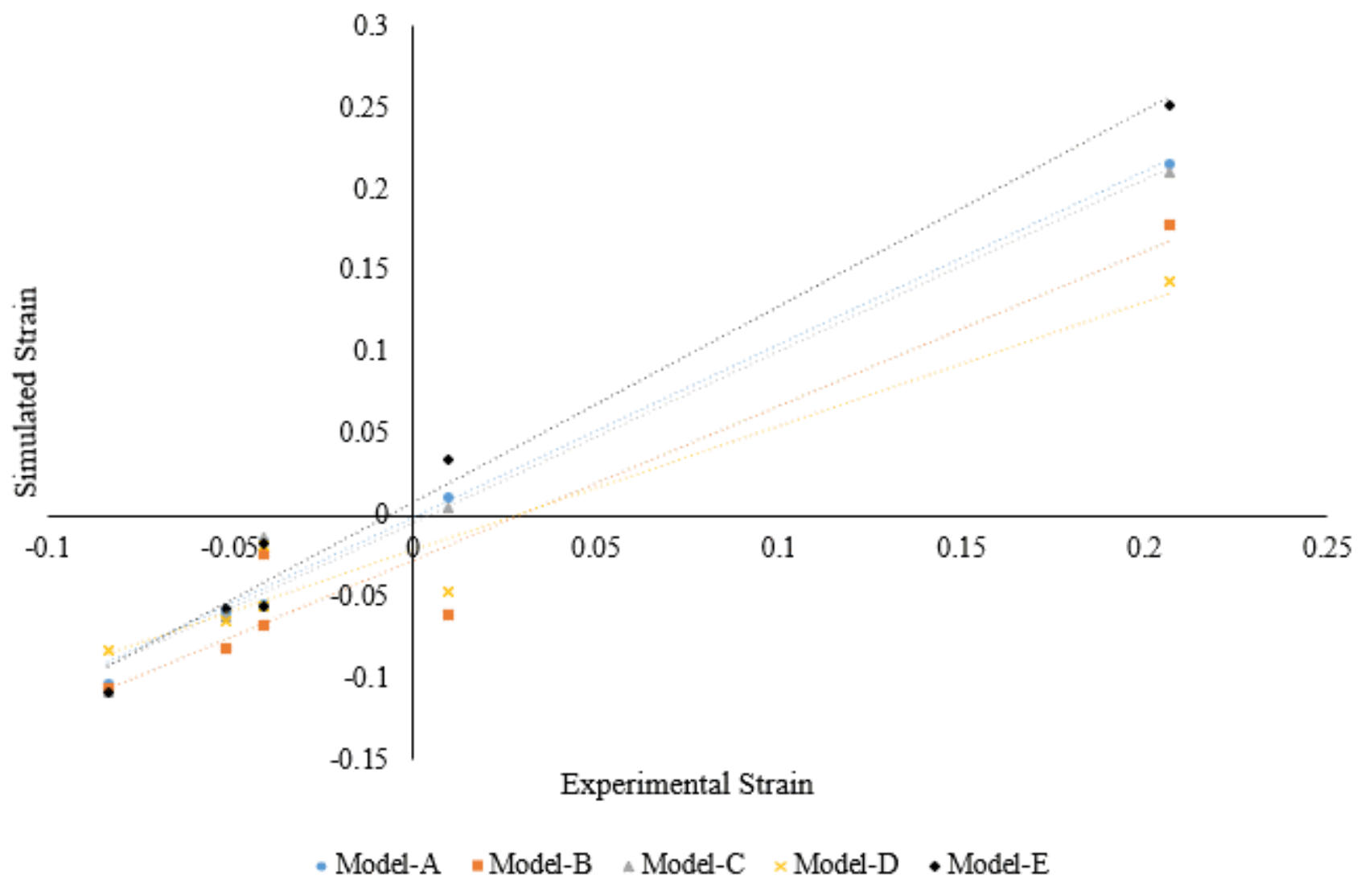

Figure 12

Comparison of experimental and simulation results of Al layer 


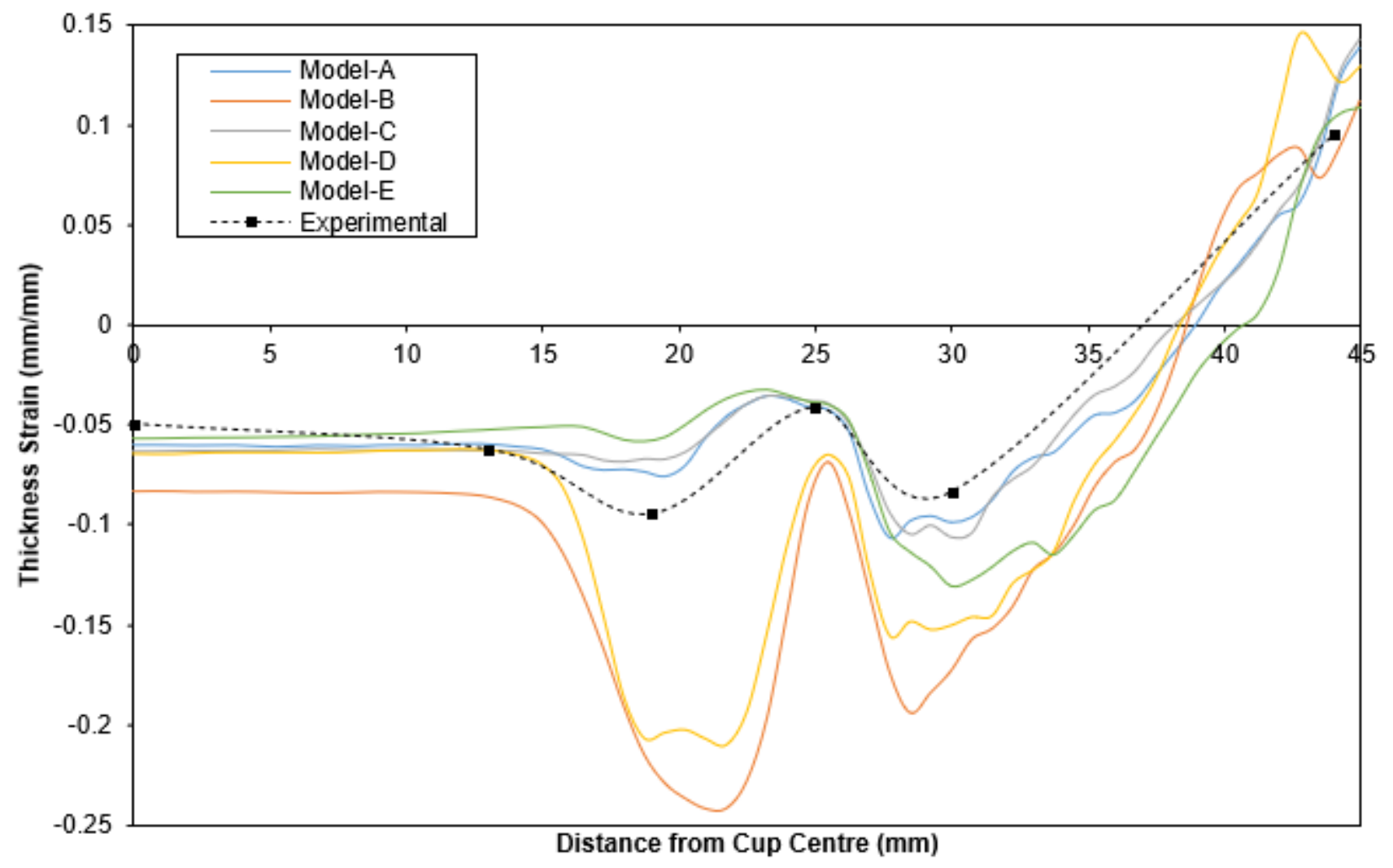

Figure 13

Comparison of the thickness strain on the steel layer of the bimetallic sheets created with Model-A, Model-B, Model-C, Model-D and Model-E in simulations with experimental results 


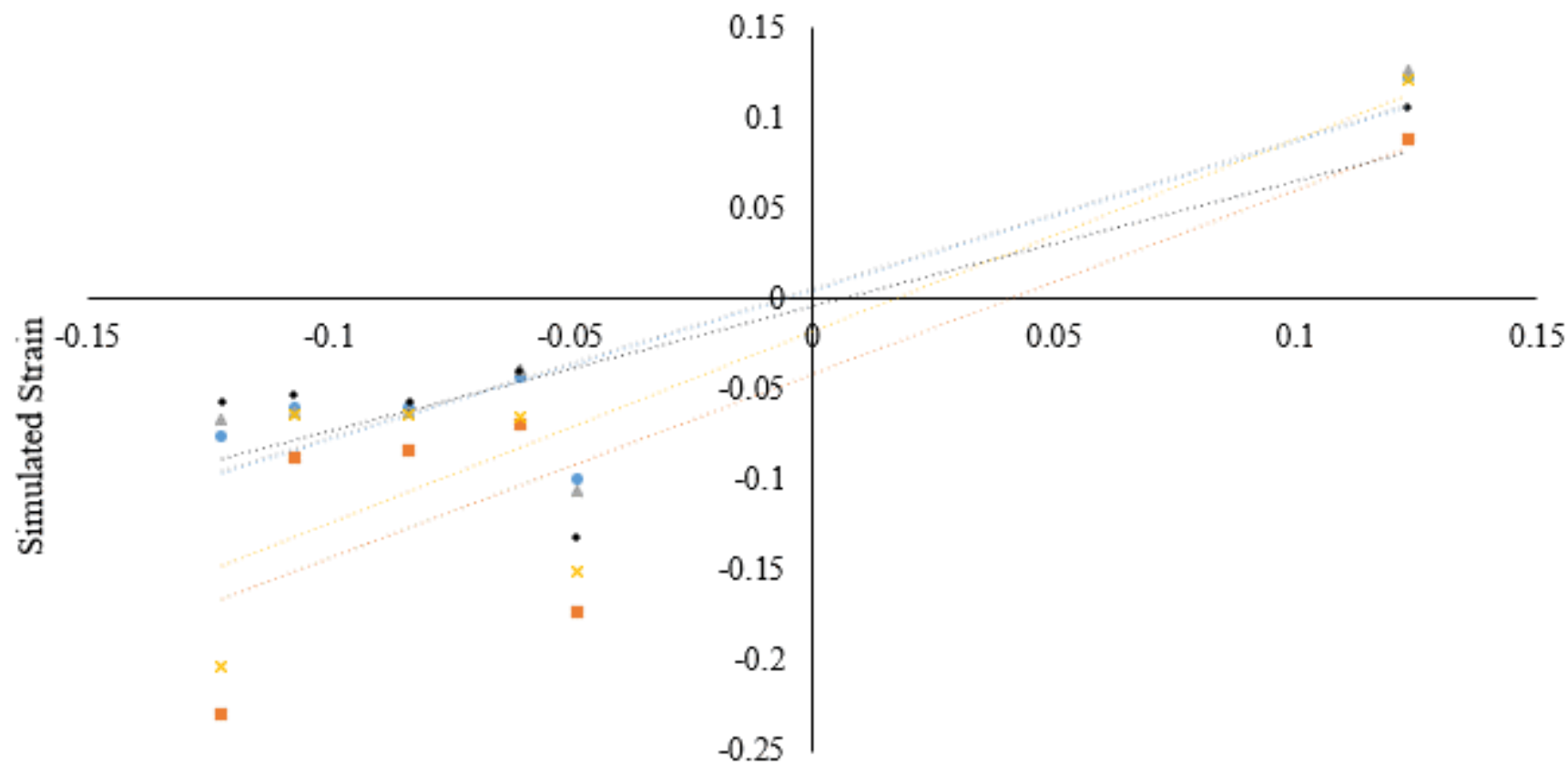

Experimental Strain

- Model-A $=$ Model-B 4 Model-C $\times$ Model-D • Model-E

Figure 14

Comparison of experimental and simulated results of St layer 


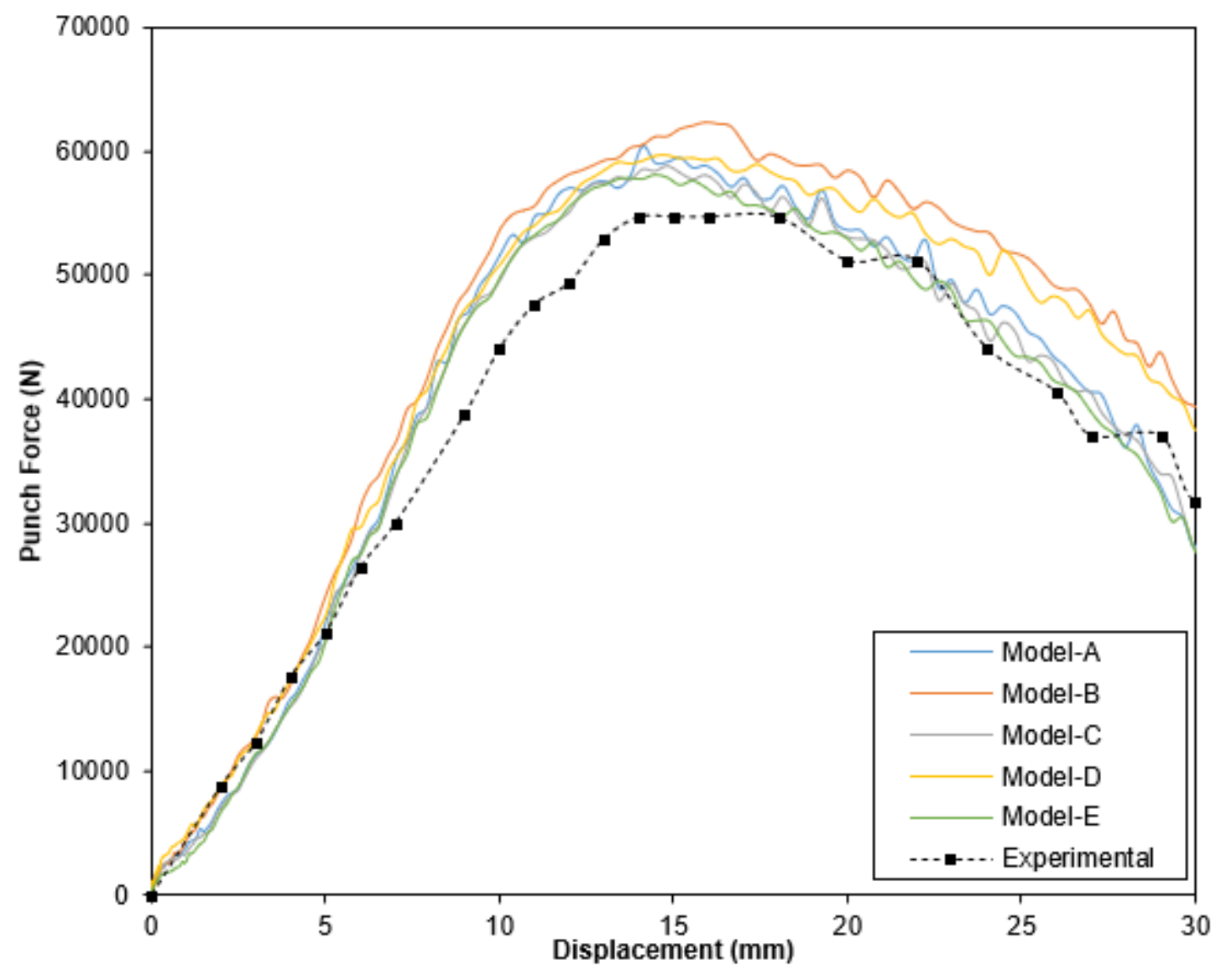

Figure 15

Comparison of punch forces obtained from deep drawing simulations with Model-A, Model-B, Model-C, Model-D and Mode-E with experimental punch force

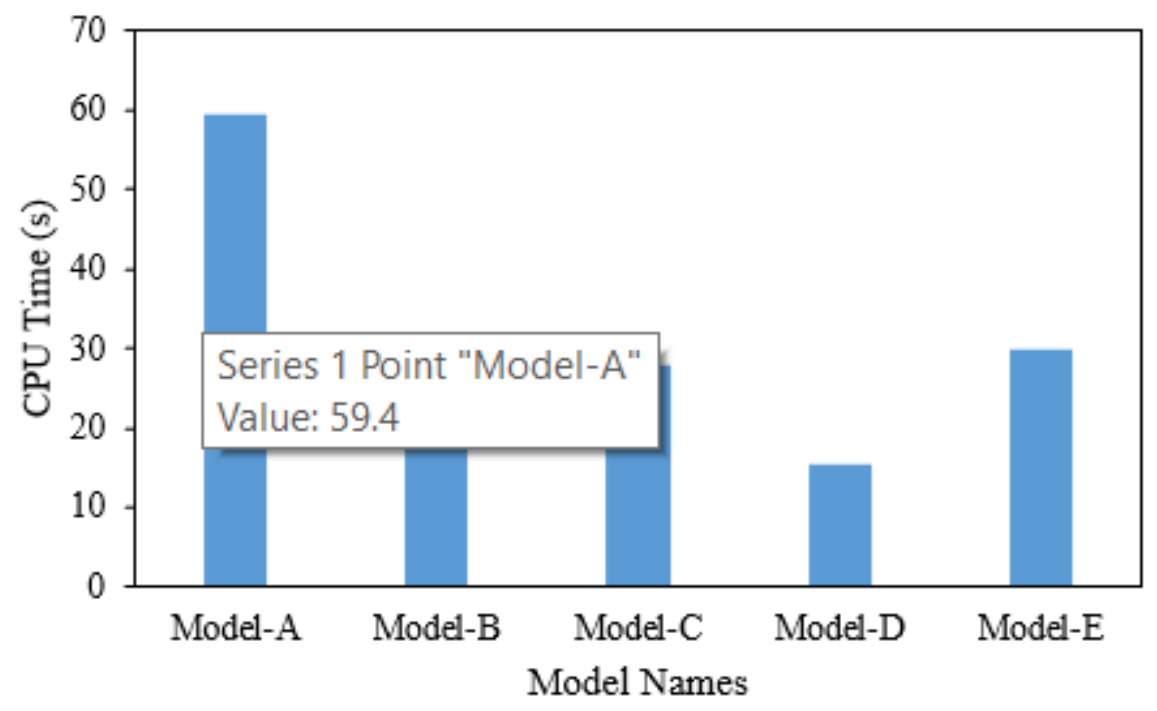

Figure 16 
CPU times of different models
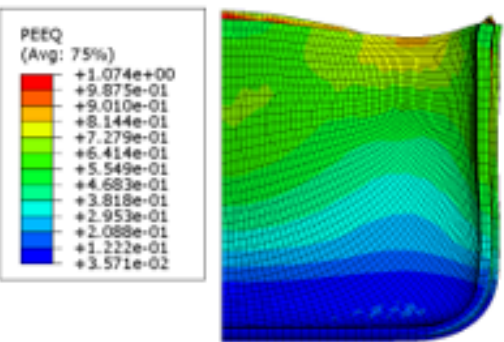

Model A

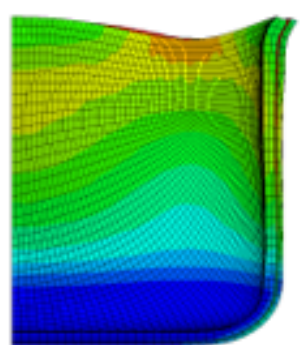

Model B

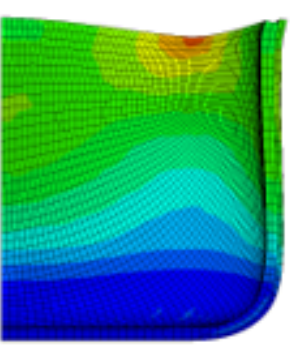

Model C

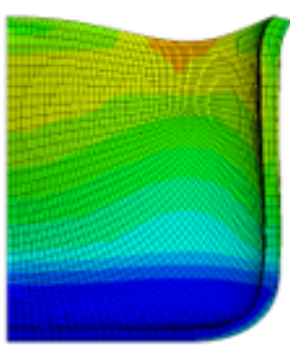

Model D

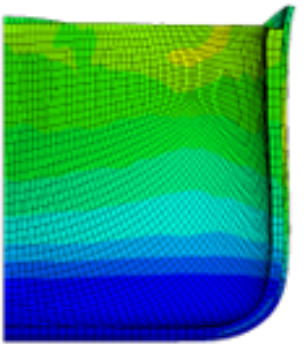

Model E

Figure 17

Strain distribution on deep drawn cups 
a) Al Layer

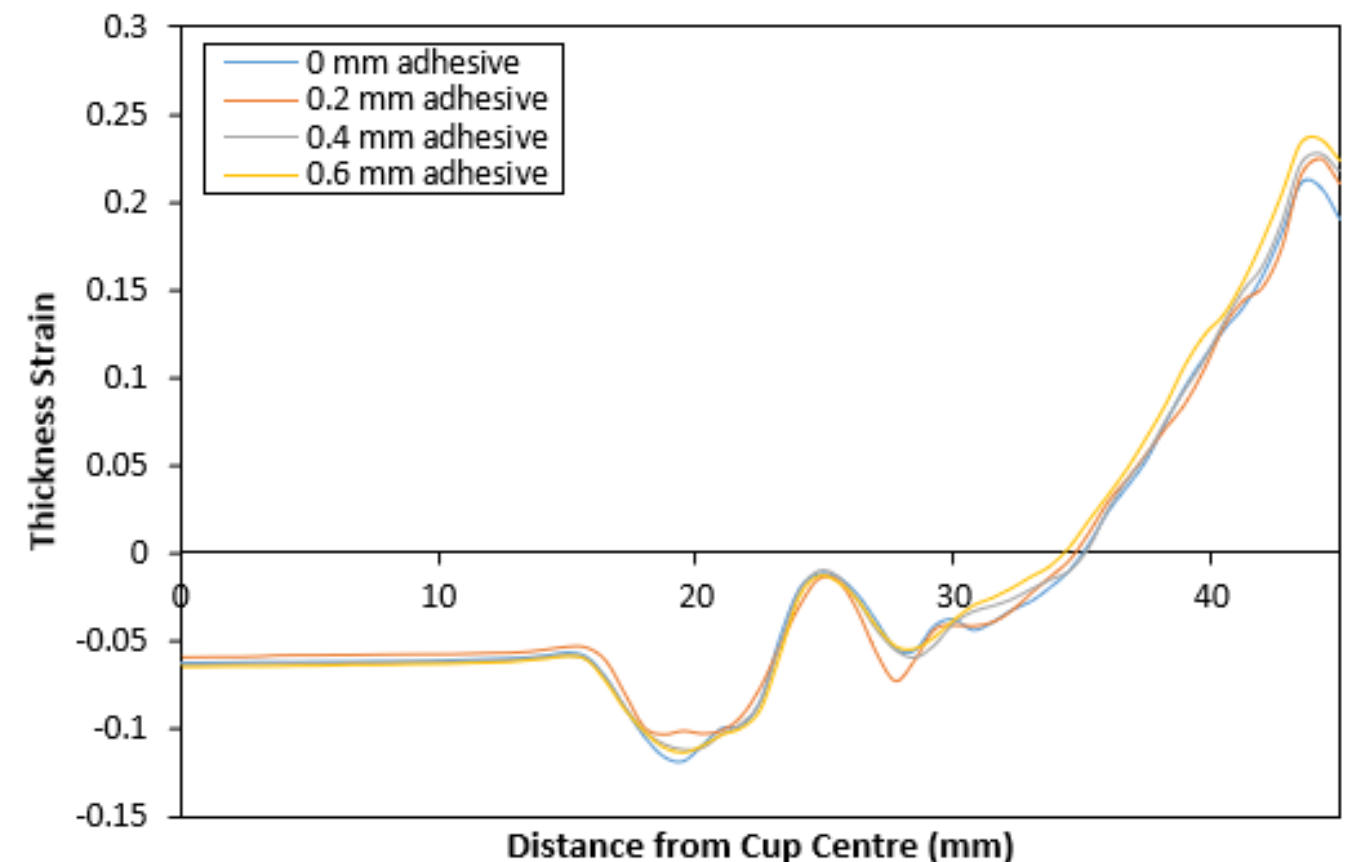

b) St Layer

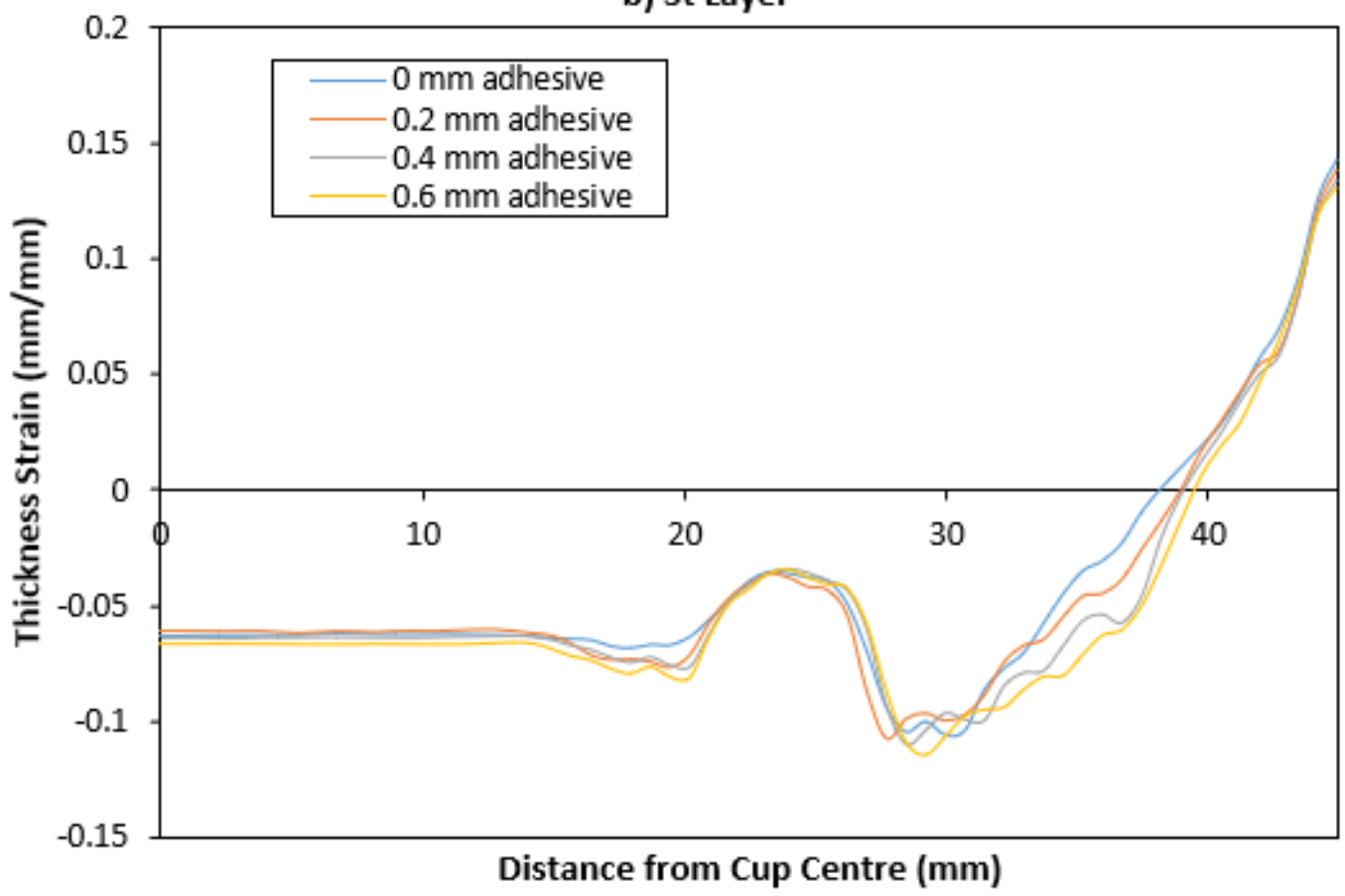

Figure 18

Strain distributions on Al and St layers for different adhesive thickness 